\title{
BORO E NITROGÊNIO NA INCIDÊNCIA DE HASTES OCAS E NO RENDIMENTO DE BRÓCOLIS
}

\author{
Boron and nitrogen on hollow stem and yield of broccoli
}

\author{
Rafael Campagnol ${ }^{1}$, Marcelo Nicolai², Simone da Costa Mello ${ }^{3}$, Camila Abrahão ${ }^{4}$, José Carlos Barbosa ${ }^{5}$
}

\begin{abstract}
RESUMO
A incidência de hastes ocas em brócolis (Brassica oleracea $\mathrm{L}$. var. italica Plenck) depende de vários fatores que afetam a absorção e o transporte de B, elemento responsável pelo aparecimento dessa desordem fisiológica. O trabalho avaliou os efeitos de quatro níveis de nitrogênio e dois níveis de boro e da interação entre eles na incidência de hastes ocas e na produção de brócolis. As doses de $\mathrm{N}\left(100,150,200\right.$ e $\left.250 \mathrm{~kg} \mathrm{ha}^{-1}\right)$ foram divididas em quatro aplicações iguais aos 15, 30, 45 e 60 dias após o transplante. O boro $\left(0,4 \mathrm{e} 8 \mathrm{~kg} \mathrm{ha}^{-1}\right)$ foi aplicado metade no plantio e a outra metade em cobertura aos 45 dias após o transplante. A massa média das inflorescências e a produção total foram diminuídas com a aplicação de B em função do crescimento mais lento das plantas provocado pela toxicidade desse elemento. Contudo, nas áreas não adubadas com B, a porcentagem de plantas com hastes ocas foi, em média, de $44,14 \%$, sendo que a incidência dessa anomalia sofreu drástica redução com a aplicação de B, onde a maior dose $\left(8 \mathrm{~kg}\right.$ ha $\left.{ }^{-1}\right)$ resultou em apenas 4,52\% de inflorescências afetadas. Doses de $\mathrm{N}$ superiores a 215,4 $\mathrm{kg} \mathrm{ha}^{-1}$ aumentaram o número de plantas com hastes ocas somente nas áreas que não receberam B.
\end{abstract}

Termos para indexação: Brassica oleracea var. italica, adubação nitrogenada, boro.

\begin{abstract}
The incidence of hollow stem in broccoli (Brassica oleracea L. var. italica Plenck) depends on several factors that affect the absorption and transport of boron, which is the element responsible for the appearance of this physiological disorder. This study evaluated the effects of four levels of nitrogen and two levels of boron and the interaction between them in the incidence of hollow stem and yield of broccoli. The levels of $\mathrm{N}\left(100,150,200\right.$ and $\left.250 \mathrm{~kg} \mathrm{ha}^{-1}\right)$ were divided into four applications equal to 15, 30, 45, and 60 days after transplant. Half of the boron $\left(0,4\right.$ and $\left.8 \mathrm{~kg} \mathrm{ha}^{-1}\right)$ was applied at planting and half in coverage at 45 days after transplanting. Average mass and total yield were reduced with B application, as a result of the slower growth of plants, having been caused by the onset of symptoms of toxicity of this element. However, in areas not fertilized with B, the percentage of plants with hollow stems was on average $44.14 \%$, while the incidence of this anomaly suffered drastic reduction in B application, where the highest level $\left(8 \mathrm{~kg} \mathrm{ha}^{-1}\right)$ resulted in only $4.52 \%$ of affected inflorescences. Levels of more than $215.4 \mathrm{~kg} \mathrm{ha}^{-1}$ of $\mathrm{N}$ have increased the number of plants with hollow stems only in areas that did not receive B.
\end{abstract}

Index terms: Brassica oleracea var. italica, nitrogen fertilization, boron.

(Recbido em 27 de agosto de 2008 e aprovado em 24 de março de 2009)

\section{INTRODUÇÃOO}

A deficiência de boro em brócolis (Brassica oleracea L. var. italica Plenck), também conhecida como podridão parda, caracteriza-se pelo aparecimento de cavidade nas partes internas do caule e de coloração escura na inflorescência (Filgueira, 2003). Entretanto, esses sintomas podem ser comuns mesmo quando o B está em nível elevado no solo, sugerindo que o aparecimento dessa anomalia é de natureza fisiológica e está relacionada à mobilidade do elemento na planta.

O B é praticamente imóvel no floema e o seu transporte é feito via xilema, que direciona o fluxo desse elemento, principalmente para os sítios de maior transpiração (folhas), que não são os locais de maior demanda por B, como as inflorescências e as partes que as compõem (hastes). Assim, fatores que interferem no movimento do B na planta podem provocar ou intensificar o aparecimento da podridão parda (Shelp et al., 1995).

Diversos autores mostram que esse distúrbio não é causado por um único fator, mas pela combinação de um ou mais fatores que intensificam o seu efeito (Vigier \& Cutcliffe, 1984; Tremblay, 1989; Babik \& Elkner, 2002), dentre os quais é possível citar as condições ambientais (temperatura, precipitação e umidade relativa do ar), as técnicas de manejo (irrigação, espaçamento e adubação) e o grau de suscetibilidade da variedade à incidência dessa

\footnotetext{
'Estudante de Mestrado da ESALQ/USP - Avenida Pádua Dias, 11 - 13418-900 - Piracicaba, São Paulo - rcampagn@esalq.usp.br 2Estudante de Doutorado da ESALQ/USP - Avenida Pádua Dias, 11-13418-900 - Piracicaba, São Paulo - marcelon@esalq.usp.br 32Departamento de Produção Vegetal, ESALQ/USP - Avenida Pádua Dias, 11-13418-900-Piracicaba, São Paulo - scmello@esalq.usp.br ${ }^{4}$ Engenheira Agrônoma - Avenida Carlos Botelho, 853, apto 6 - 13416-145 - Piracicaba, São Paulo - ca_abrahao@yahoo.com.br ${ }^{5}$ Departamento de Ciências Exatas, FCAV/UNESP - Campus de Jaboticabal, Via de acesso Prof. Paulo Donato Castellane, s/n - $14884-900$ Jaboticabal, São Paulo - jcbarbosa@fcav.unesp.br
} 
anomalia. Em função disso, os trabalhos sobre os efeitos dos fatores que interferem na incidência de podridão parda têm mostrado resultados distintos.

Quanto à adubação, as pesquisas mostram que, além do boro, o nitrogênio afeta o aparecimento de hastes ocas em brócolis, pois níveis elevados de fertilizantes nitrogenados aumentam a ocorrência dessa desordem fisiológica (Tremblay, 1989; Bélec et al., 2001). Para Mello et al. (1997), a porcentagem de plantas de brócolis com hastes ocas foi reduzida com o fornecimento de $2,16 \mathrm{~kg}$ ha${ }^{1}$ de B. Shattuck \& Shelp (1987), por sua vez, não obtiveram relação entre a incidência dessa anomalia em brócolis e a aplicação de B no solo. Em brócolis, a aplicação de $90 \mathrm{~kg}$ $\mathrm{ha}^{-1}$ de $\mathrm{N}$ em cobertura aumentou o índice de podridão parda de 21\% (sem N) para 52\% (Vigier \& Cutcliffe, 1984), sendo que para Scaife \& Wurr (1990) a adição de $225 \mathrm{~kg} \mathrm{ha}^{-1}$ de $\mathrm{N}$ reduziu o aparecimento dessa desordem fisiológica.

De acordo com Gupta \& Cutcliffe (1973), deve haver um balanço entre N e B nas plantas de brócolis. Isso foi observado em experimento realizado por Kotur (1997), onde a severidade da incidência de talo oco, notadamente, foi reduzida com o aumento das doses de $\mathrm{N}$ somente quando o fornecimento de B foi adequado.

Portanto, outros estudos precisam ser realizados para verificar o comportamento do B e do N na ocorrência de hastes ocas em brócolis, em virtude das variações nas condições de cultivo, que interferem na resposta da planta ao fornecimento desses elementos. Neste trabalho, objetivou-se avaliar os efeitos da aplicação de N e B e da interação entre eles na incidência de hastes ocas e na produção de brócolis, em Piracicaba (SP).

\section{MATERIAIS E MÉTODOS}

O experimento foi conduzido no Departamento de Produção Vegetal da Escola Superior de Agricultura "Luiz de Queiroz" (USP), município de Piracicaba (SP), durante o período de 13 de abril a 09 de julho de 2006.

O solo da área, Nitossolo Vermelho Eutrófico Típico, apresentou as seguintes características: matéria orgânica $($ dicromato de potássio $)=31 \mathrm{mg} \mathrm{dm}^{-3} ; \mathrm{P}($ resina $)=312 \mathrm{mg} \mathrm{dm}^{-}$ 3; $\mathrm{K}$ (resina) $=15,6 \mathrm{mmolc} \mathrm{dm}^{-3} ; \mathrm{Ca}($ resina $)=89 \mathrm{mmolc} \mathrm{dm}^{-3} ; \mathrm{Mg}$ (resina) $=36 \mathrm{mmolc} \mathrm{dm}^{-3} ; \mathrm{pH}\left(\mathrm{CaCl}_{2}\right)=6,1 ; \mathrm{S}=90 \mathrm{mg} \mathrm{dm}^{-3} ;$ CTC $=160,6 \mathrm{mmolc} \mathrm{dm}^{-3} ; \mathrm{V} \%=88 ; \mathrm{B}$ (água quente) $=0,84 \mathrm{mg} \mathrm{dm}^{-3}$.

$\mathrm{O}$ delineamento experimental foi em blocos ao acaso com quatro repetições, sendo os tratamentos compostos pelas combinações de três níveis de boro $\left(0,4\right.$ e $\left.8 \mathrm{~kg} \mathrm{ha}^{-1}\right)$ e quatro níveis de nitrogênio $\left(100,150,200\right.$ e $\left.250 \mathrm{~kg} \mathrm{ha}^{-1}\right)$. O nitrogênio, na forma de nitrato de amônio ( $32 \%$ de $\mathrm{N})$, foi parcelado em quatro aplicações iguais, aos 15, 30, 45 e 60 dias, após o transplante das mudas. O boro foi aplicado, por meio de um fertilizante granulado (9\% de B), em duas etapas, metade da dose no plantio e a outra metade em cobertura, localizada a $5 \mathrm{~cm}$ da haste da planta, aos 45 dias após o transplante das mudas.

Cada parcela foi constituída por 16 plantas distribuídas em duas linhas sobre um canteiro de 1,20 $\mathrm{m}$ de largura, no espaçamento de $0,5 \mathrm{~m}$ entre plantas e $0,9 \mathrm{~m}$ entre linhas. A parcela útil foi composta pelas 12 plantas centrais. As parcelas apresentavam $0,5 \mathrm{~m}$ de distância entre si.

O cultivar de brócolis utilizado foi o híbrido BRO 68 , caracterizado por inflorescências com massa média de 350 a 400 gramas e como não susceptível à podridão parda.

As mudas de brócolis foram produzidas em bandejas de isopor de 200 células, preenchidas com substrato orgânico à base de casca de pinus, em ambiente protegido. O transplante das mudas para os canteiros ocorreu aos 30 dias após a semeadura.

Aos 54 dias após o transplante, foram coletadas quatro folhas por parcela, uma folha de cada planta, retirando-se a folha desenvolvida no período da formação da cabeça. As folhas foram lavadas e secadas em estufas a $65^{\circ} \mathrm{C}$ por 48 horas. Posteriormente, procedeu-se a moagem do material vegetal para a determinação dos teores de macronutrientes e de B (Malavolta et al., 1997).

A colheita iniciou-se aos 60 dias após o transplante das mudas (DAT) e foi realizada até os 87 DAT. As inflorescências foram avaliadas quanto à sua massa e presença de hastes ocas. Com base nesses últimos dados, foram calculadas a produção total $\left(\mathrm{t} \mathrm{ha}^{-1}\right)$, a produção comercial $\left(\mathrm{t} \mathrm{ha}^{-1}\right)$ e a porcentagem de plantas com hastes ocas. A produção comercial foi definida pela diferença entre a produção total e a produção de plantas com hastes ocas. Os resultados obtidos foram submetidos às análises de variância e de regressão polinomial.

\section{RESULTADOS E DISCUSSÃO}

O peso médio das inflorescências e a produção total diminuíram com a aplicação de boro (Figuras 1 e 2). Esse fato ocorreu, provavelmente em função do modo de aplicação do fertilizante, ou seja, metade da dose no plantio e a outra metade em cobertura, localizada a $5 \mathrm{~cm}$ do caule das plantas, que provocou sintomas de toxicidade de B, caracterizado pela queimadura das bordas das folhas. Em Vigier \& Cutcliffe (1984) e Mello et al. (1997), o fornecimento de B em faixas ao longo da linha de plantio e nas covas, respectivamente, também foi responsável pela ocorrência de sintomas de toxicidade do elemento em plantas de brócolis. Para Pizetta et al. (2005), o B colocado no sulco de plantio a $15 \mathrm{~cm}$ de profundidade, nas taxas de $2,4,6$ e 8 $\mathrm{kg} \mathrm{ha}^{-1}$, com fertilizantes minerais e vermicomposto de esterco de curral não ocasionou sintomas de toxicidade às plantas de brócolis 'Legacy', evidenciando a influência do modo de aplicação do nutriente. 


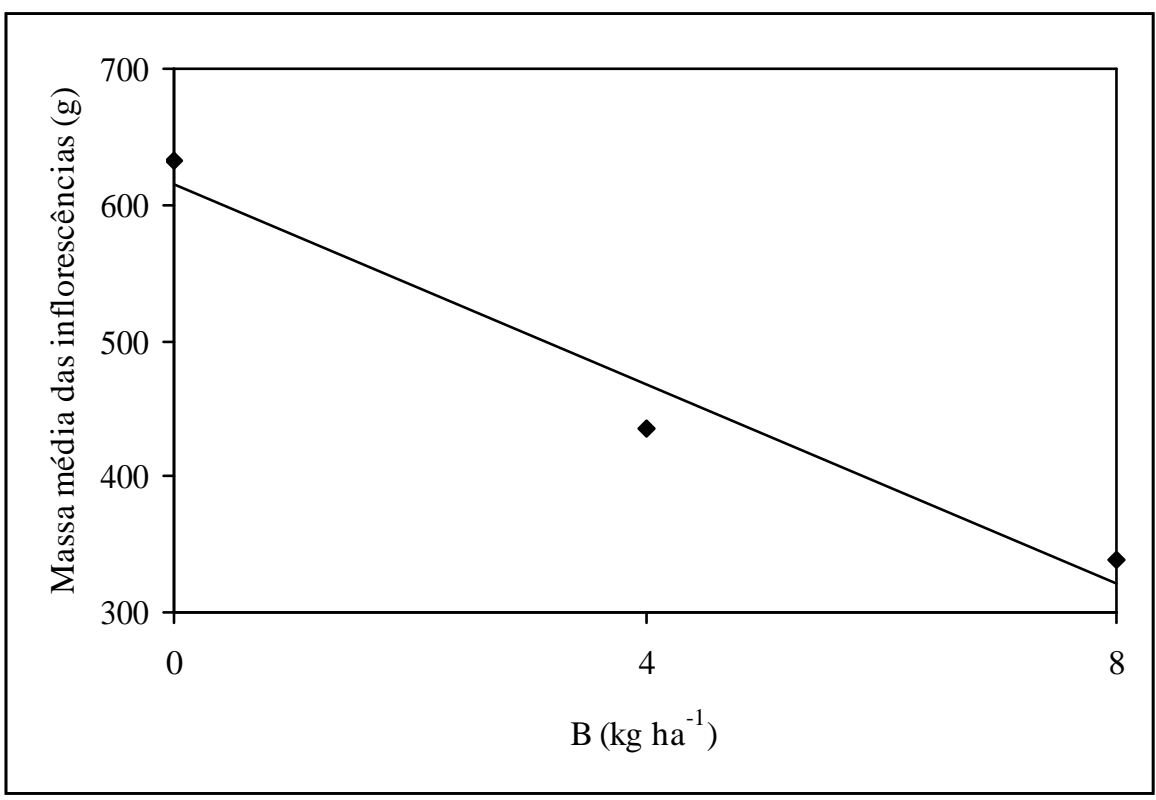

\begin{tabular}{|cccc|}
\hline Tratamento & $\mathrm{F}$ & $\mathrm{R}^{2}$ & Equação \\
\hline$\bullet$ boro & $90,53 * *$ & 0,9627 & $\mathrm{y}=614,8854-36,7109 \mathrm{x}$ \\
\hline
\end{tabular}

Figura 1 - Massa média das inflorescências em função da aplicação de B.

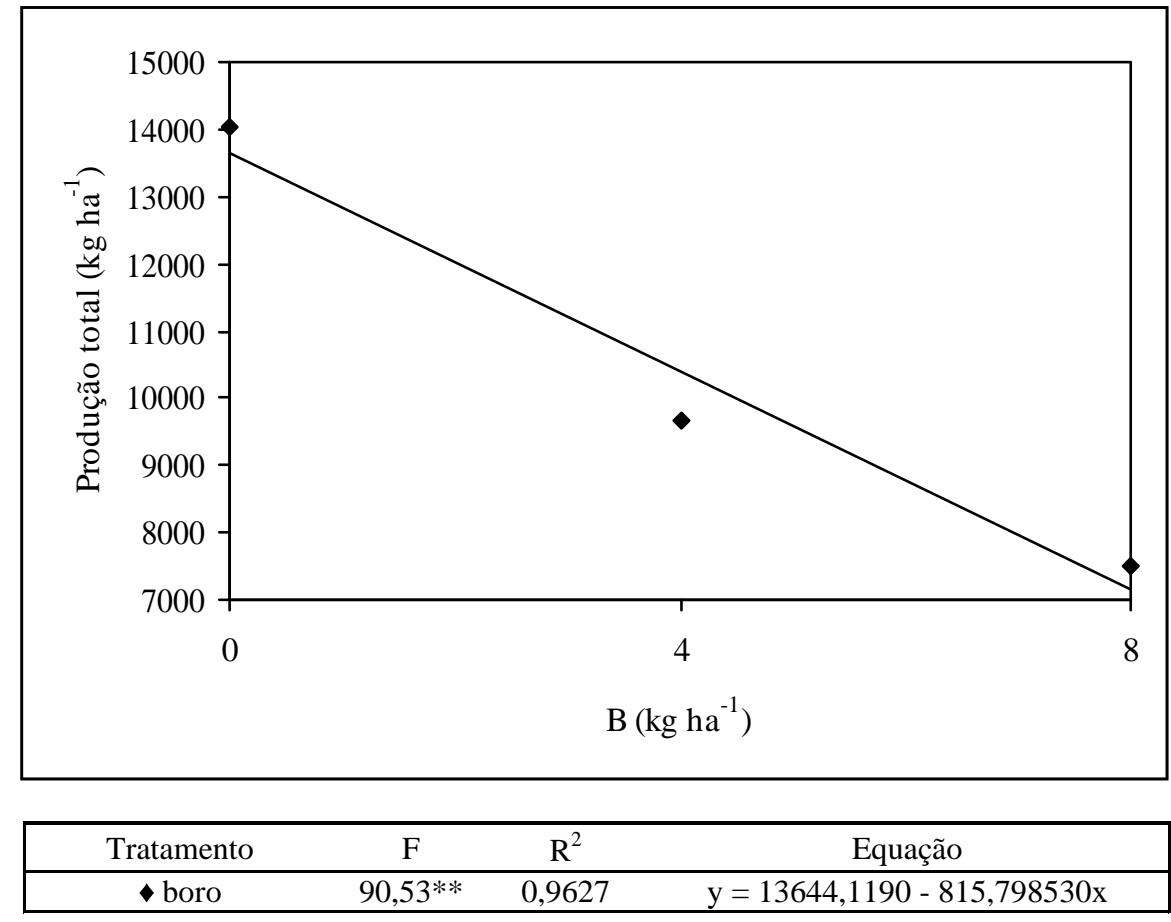

Figura 2 - Produção total $\left(\mathrm{kg} \mathrm{ha}^{-1}\right)$ em função da aplicação de B. 
As análises de variância, por sua vez, não acusaram efeitos significativos do $\mathrm{N}$ sobre a massa média das inflorescências e produção total de brócolis. Bracy et al. (1995) também não encontraram resposta dessa hortaliça quanto à produção e massa das inflorescências pela aplicação de 45 ou $90 \mathrm{~kg} \mathrm{ha}^{-1}$ de $\mathrm{N}$ no plantio e 134 a $258 \mathrm{~kg}$ ha $^{-1}$ de N em cobertura. Em Babik \& Elkner (2002), a aplicação de $100 \mathrm{~kg} \mathrm{ha}^{-1}$ de $\mathrm{N}$ em pré-plantio e $200 \mathrm{~kg} \mathrm{ha}^{-1}$ de $\mathrm{N}$ em pré-plantio ou cobertura não aumentaram a massa média da inflorescência de brócolis, não irrigado.

A porcentagem de plantas com hastes ocas sofreu interação entre as doses de $\mathrm{N}$ e de B (Figuras 3, 4 e 5). A adubação nitrogenada influenciou essa característica somente nas áreas não adubadas com boro, sendo que a aplicação de $\mathrm{N}$ reduziu a incidência de hastes ocas até a dose de $215,4 \mathrm{~kg} \mathrm{ha}^{-1}$, aumentando-a a partir desse valor (FIGURA 4). Esse resultado está de acordo com os obtidos por Everaarts \& Putter (2000), Bélec et al. (2001) e Babik \& Elkner (2002), confirmando que doses elevadas de $\mathrm{N}$ induzem maior ocorrência de cavidade nas hastes de brócolis.

Segundo Malavolta et al. (1997), há inibição não competitiva entre o B e o N. Dessa forma, o excesso desse último elemento pode reduzir a absorção do $\mathrm{B}$, o que levaria ao aumento do número de plantas com hastes ocas. Outra explicação para a maior ocorrência dessa anomalia se baseia no fato do $\mathrm{N}$ acelerar o crescimento da planta, induzindo a deficiência de B, uma vez que esse elemento é imóvel no floema (Shelp et al., 1995).

As aplicações de B diminuíram a incidência de hastes ocas em todas as doses de N (Figura 5). O mesmo fato foi observado por Mello et al. (1997), em solo com 1,07 $\mathrm{mg} \mathrm{kg}^{-1}$ de $\mathrm{B}$, sendo que o fornecimento de $2,16 \mathrm{~kg} \mathrm{ha}^{-1}$ do elemento diminuiu a incidência dessa anomalia em plantas de brócolis. Batal et al. (1997) também obtiveram redução no número de plantas com hastes ocas, nesse caso de couve-flor, por meio da aplicação de 4,4 e $8,8 \mathrm{~kg} \mathrm{ha}^{-1}$ de B.

Cabe ressaltar, que nas áreas não adubadas com B, a porcentagem média de plantas com hastes ocas foi elevada, da ordem de $44 \%$. A explicação para esse comportamento baseia-se, principalmente, na mobilidade do elemento na planta. O B é transportado basicamente via xilema e direcionado para os sítios de maior transpiração (folhas), que não são os sítios de maior demanda (inflorescência), cuja redistribuição por meio do floema praticamente não ocorre (Shelp et al., 1995), o que justifica a necessidade de aplicação desse elemento mesmo em solo com teor alto, como o encontrado nesse experimento $(0,84$ $\mathrm{mg} \mathrm{dm}{ }^{-3} \mathrm{de} B$ ).
Os teores foliares de $\mathrm{N}$ aumentaram com a adubação nitrogenada (Figura 6), concordando com os resultados obtidos por Vigier \& Cutcliffe (1984) para plantas de brócolis adubadas com $90 \mathrm{~kg} \mathrm{ha}^{-1}$ de $\mathrm{N}$ e por Bélec et al. (2001) para plantas de brócolis que receberam entre 50 e $250 \mathrm{~kg} \mathrm{ha}^{-1} \mathrm{de}$ N. Os valores encontrados desse elemento $(37,8$ a 56,28 g $\mathrm{kg}^{-1}$ ) estão dentro da faixa considerada adequada por Trani \& Raij (1996)

Já, os teores de Ca nas folhas diminuíram com a aplicação de N (Figura 7), provavelmente pela competição entre os íons $\mathrm{Ca}^{++}$e os íons $\mathrm{NH}_{4}^{+}$, uma vez que a fonte de nitrogênio utilizada foi o nitrato de amônio, que contém $16,5 \%$ de N na forma amoniacal. Sabe-se que os íons amônio são preferencialmente absorvidos em relação ao cálcio, provocando redução na absorção desse elemento, consequentemente no seu teor nas folhas.

Os teores foliares de $\mathrm{B}$ e $\mathrm{Ca}$ aumentaram linearmente em função da adubação com boro (Figuras 8 e 9).

Resultados semelhantes foram obtidos por Vigier \& Cutcliffe (1984) para o B, onde a aplicação desse elemento (4 e $8 \mathrm{~kg} \mathrm{ha}^{-1}$ ) aumentou o seu teor foliar, sendo que o maior nível observado nas áreas com $8 \mathrm{~kg} \mathrm{ha}^{-1}$ de B (42 mg $\mathrm{kg}^{-1}$ ) resultou em toxicidade às plantas de brócolis. Nesse experimento, as maiores concentrações de B (80,21 a 127,67 $\mathrm{mg} \mathrm{kg}^{-1}$ ), que também ocorreram nas áreas que receberam 8 $\mathrm{kg} \mathrm{ha}^{-1}$ do elemento e que foram responsáveis pelo aparecimento dos sintomas mais severos de toxicidade nas plantas, estão acima da faixa considerada adequada por Gupta \& Cutcliffe (1984), que é de 13 a $70 \mathrm{mg} \mathrm{kg}^{-1}$.

Quanto ao Ca, sabe-se que o B possui correlação positiva com ele. Plantas deficientes em B apresentam transporte deficiente de $\mathrm{Ca}$ para os tecidos vegetais (Marshner, 1995). Dessa forma, a aplicação desse micronutriente pode aumentar a concentração de Ca nas folhas maduras, jovens e inflorescências, o que explica os resultados obtidos. Por outro lado, François (1986) não observou aumento na concentração de $\mathrm{Ca}$ em folhas de brócolis com a aplicação de boro via água de irrigação (1; 4; 8; 12; 16 e $20 \mathrm{mg} \mathrm{L}^{-1}$ ).

Os teores foliares de $\mathrm{P}, \mathrm{K}, \mathrm{Mg}$ e $\mathrm{S}$ não foram influenciados pelas aplicações de $\mathrm{N}$ e de $\mathrm{B}$, cujos valores médios encontrados foram de: 6,59; 54,98; 3,84 e 8,03 $\mathrm{g} \mathrm{kg}^{-1}$, respectivamente. Com exceção do $\mathrm{K}$, os teores foliares dos nutrientes estão inseridos nas faixas consideradas adequadas para o brócolis (Trani \& Raij, 1996). O nível de $\mathrm{K}$, por sua vez, está um pouco acima do teor máximo adequado, segundo esses autores. Para François (1986) a aplicação de B na água de irrigação, também não afetou significativamente as concentrações de $\mathrm{P}, \mathrm{K}$ e $\mathrm{Mg}$ nas folhas de brócolis. 


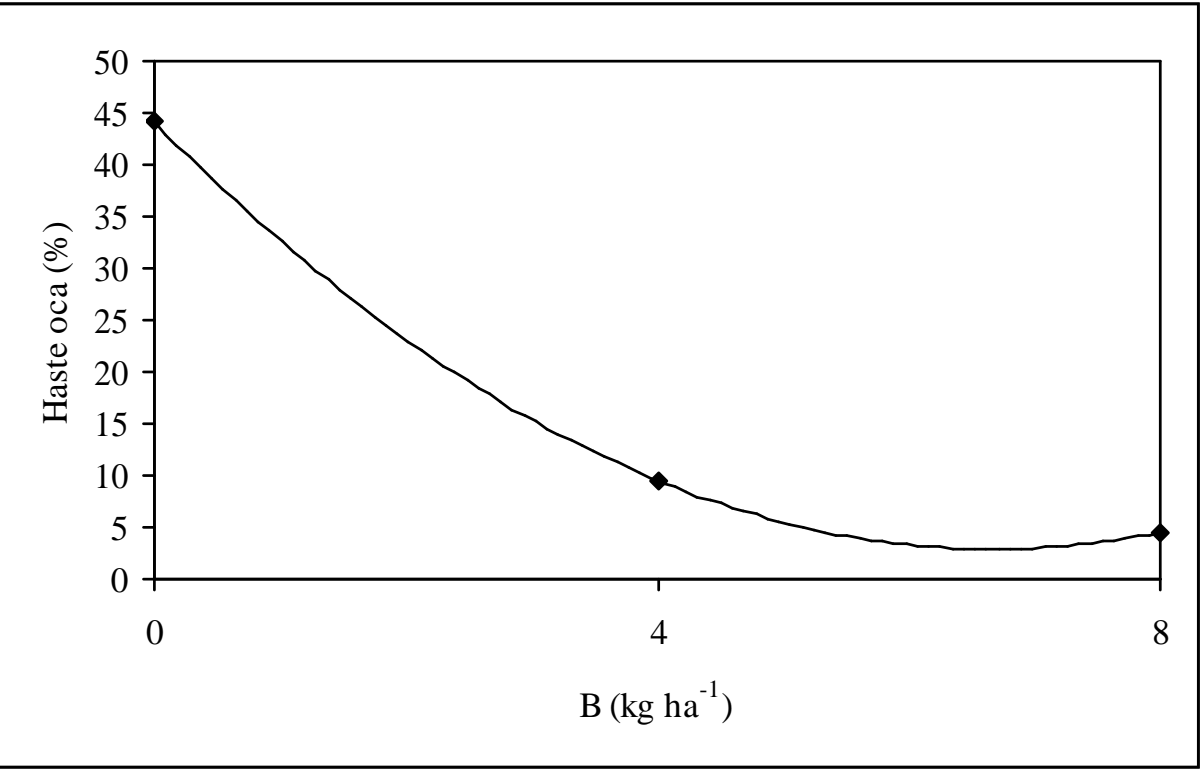

\begin{tabular}{|cccc|}
\hline Tratamento & $\mathrm{F}$ & $\mathrm{R}^{2}$ & Equação \\
\hline$\bullet$ boro & $13,94 * *$ & 1 & $\mathrm{y}=44,1431-12,3588 \mathrm{x}+0,9257 \mathrm{x}^{2}$ \\
\hline
\end{tabular}

Figura 3 - Porcentagem de plantas com haste oca em função da aplicação de B.

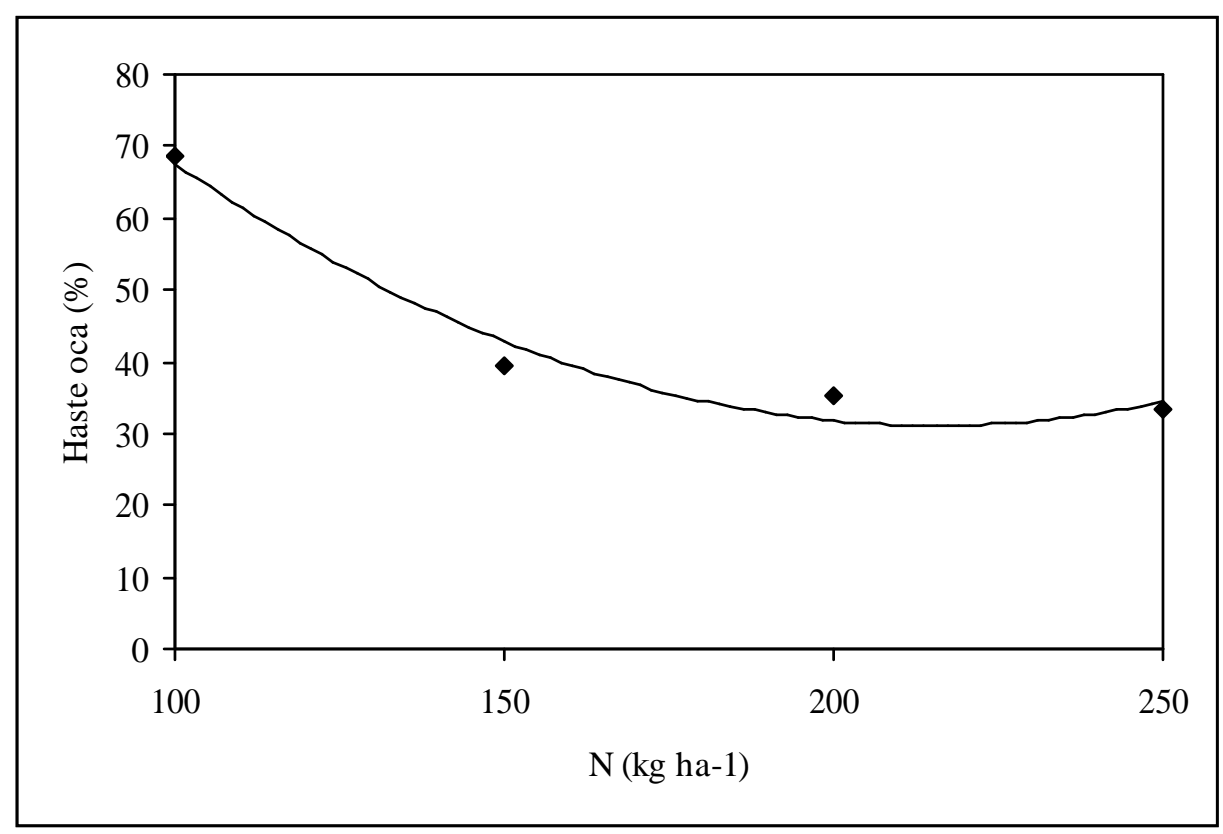

\begin{tabular}{|cccc|}
\hline Tratamento & $\mathrm{F}$ & $\mathrm{R}^{2}$ & Equação \\
\hline N dentro de B0 & $4,47 *$ & 0,9679 & $\mathrm{y}=158,2098-1,1799 \mathrm{x}+0,0027 \mathrm{x}^{2}$ \\
\hline
\end{tabular}

Figura 4 - Porcentagem de plantas com haste oca em função da aplicação de N, na ausência de B. 


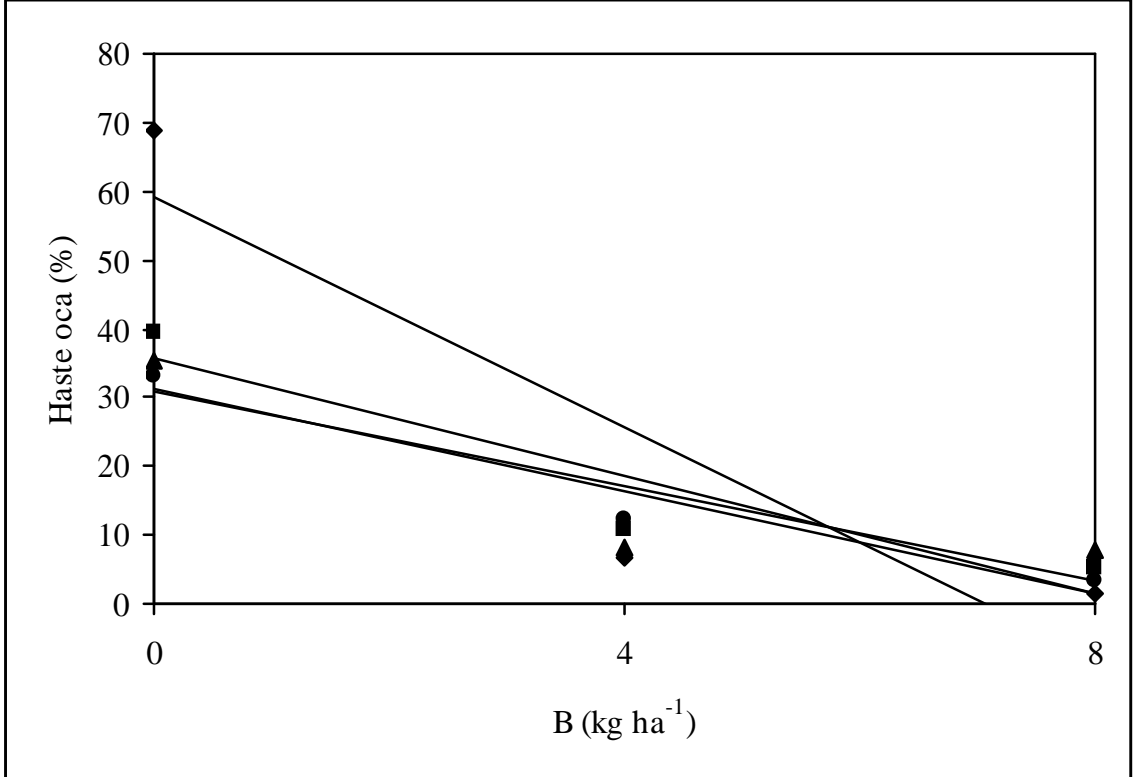

\begin{tabular}{|cccc|}
\hline Tratamento & F & R2 & Equações \\
\hline B dentro de N 100 & $53,60^{* *}$ & 0,8056 & $\mathrm{y}=59,2362-8,3853 \mathrm{x}$ \\
- B dentro de N 150 & $13,98^{* *}$ & 0,8731 & $\mathrm{y}=35,6050-4,2818 \mathrm{x}$ \\
A B dentro de N 200 & $8,95^{* *}$ & 0,7642 & $\mathrm{y}=30,8233-3,4256 \mathrm{x}$ \\
- B dentro de N 250 & $10,53^{* *}$ & 0,9450 & $\mathrm{y}=31,1583-3,7181 \mathrm{x}$ \\
\hline
\end{tabular}

Figura 5 - Porcentagem de plantas com haste oca em função da aplicação de B, para cada dose de N.

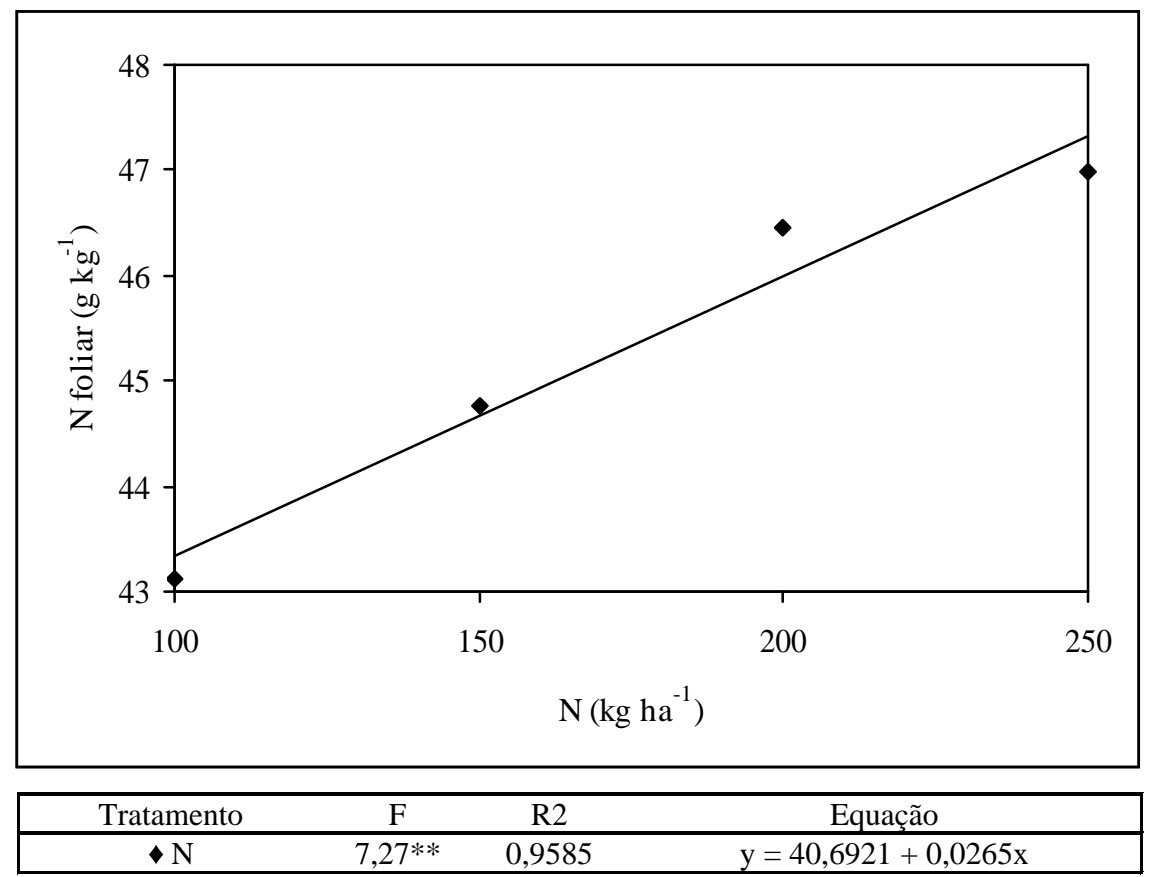

Figura 6 - Teor foliar de $\mathrm{N}\left(\mathrm{g} \mathrm{kg}^{-1}\right)$ em função da aplicação de $\mathrm{N}$.

Ciênc. agrotec., Lavras, v. 33, n. 6, p. 1477-1485, nov./dez., 2009 


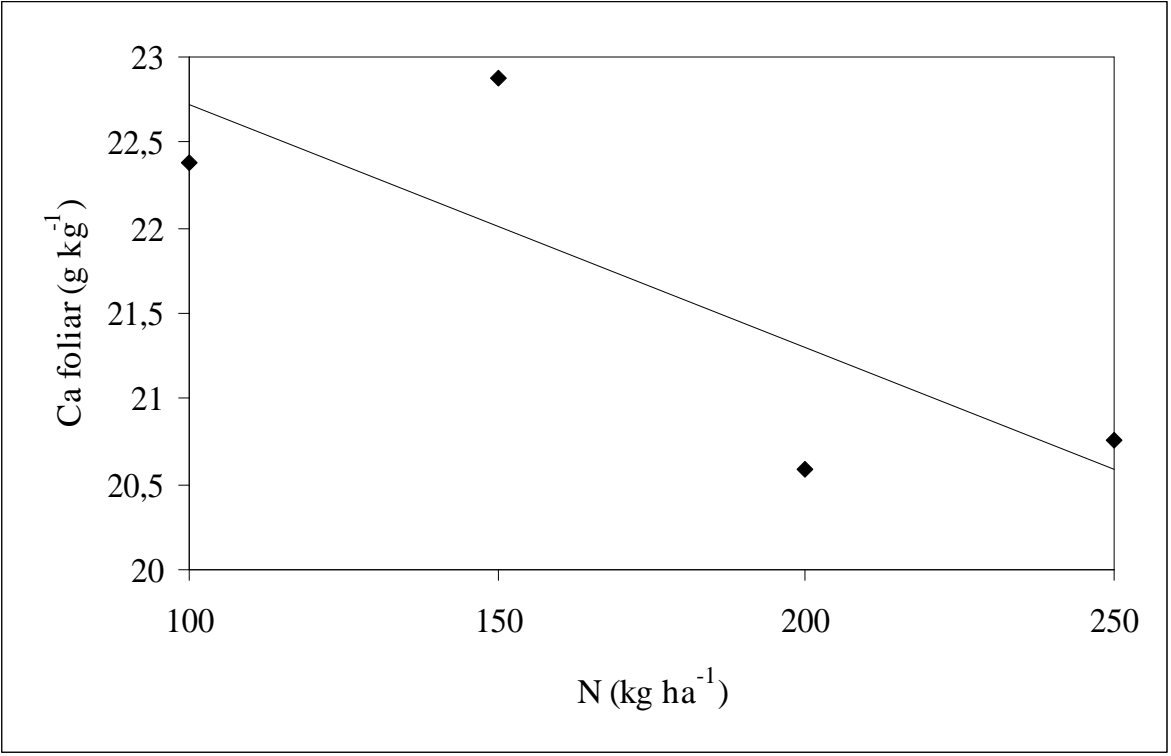

\begin{tabular}{|cccc|}
\hline Tratamento & $\mathrm{F}$ & $\mathrm{R}^{2}$ & Equação \\
\hline$\bullet \mathrm{N}$ & $5,65^{*}$ & 0,6432 & $\mathrm{y}=24,1541-0,0142 \mathrm{x}$ \\
\hline
\end{tabular}

Figura 7 - Teor foliar de $\mathrm{Ca}\left(\mathrm{g} \mathrm{kg}^{-1}\right)$ em função da aplicação de $\mathrm{N}$.

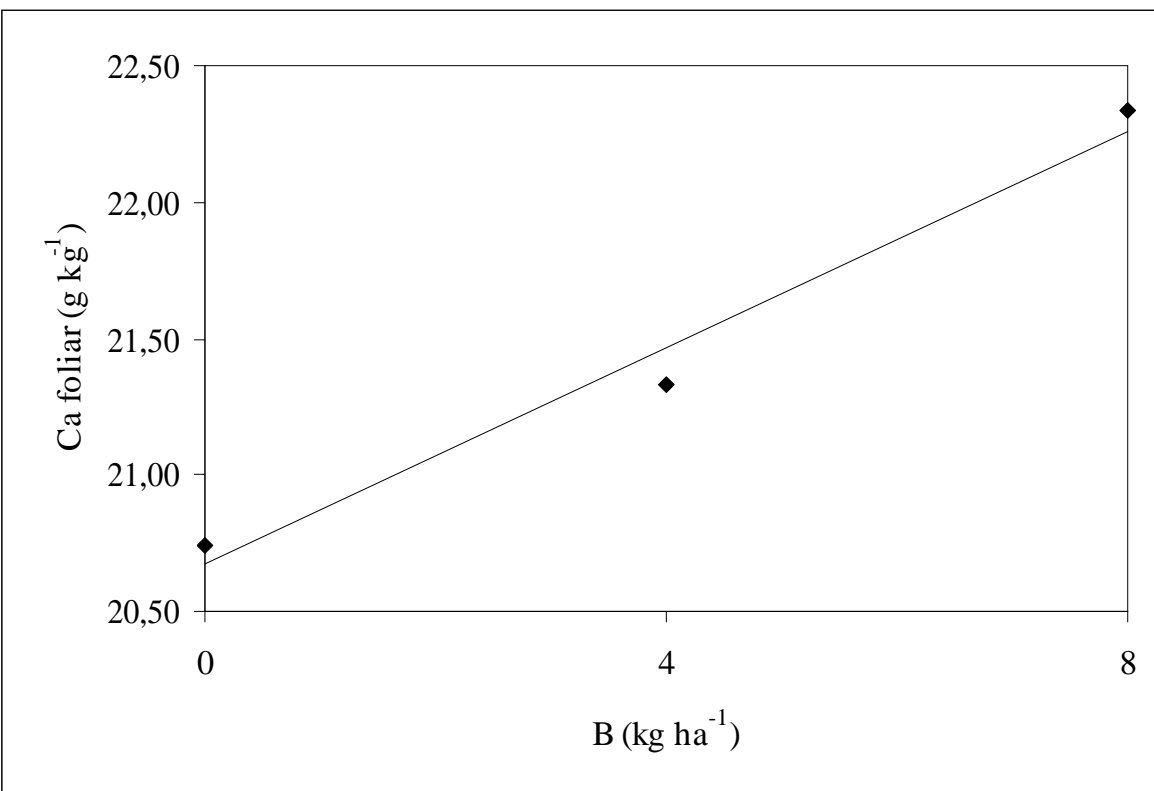

\begin{tabular}{|cccc|}
\hline Tratamento & $\mathrm{F}$ & $\mathrm{R} 2$ & Equação \\
\hline$\bullet \mathrm{B}$ & $6,76^{*}$ & 0,9365 & $\mathrm{y}=20,5828+0,2675 \mathrm{x}$ \\
\hline
\end{tabular}

Figura 8 - Teor foliar de $\mathrm{Ca}\left(\mathrm{g} \mathrm{kg}^{-1}\right)$ em função da aplicação de B. 


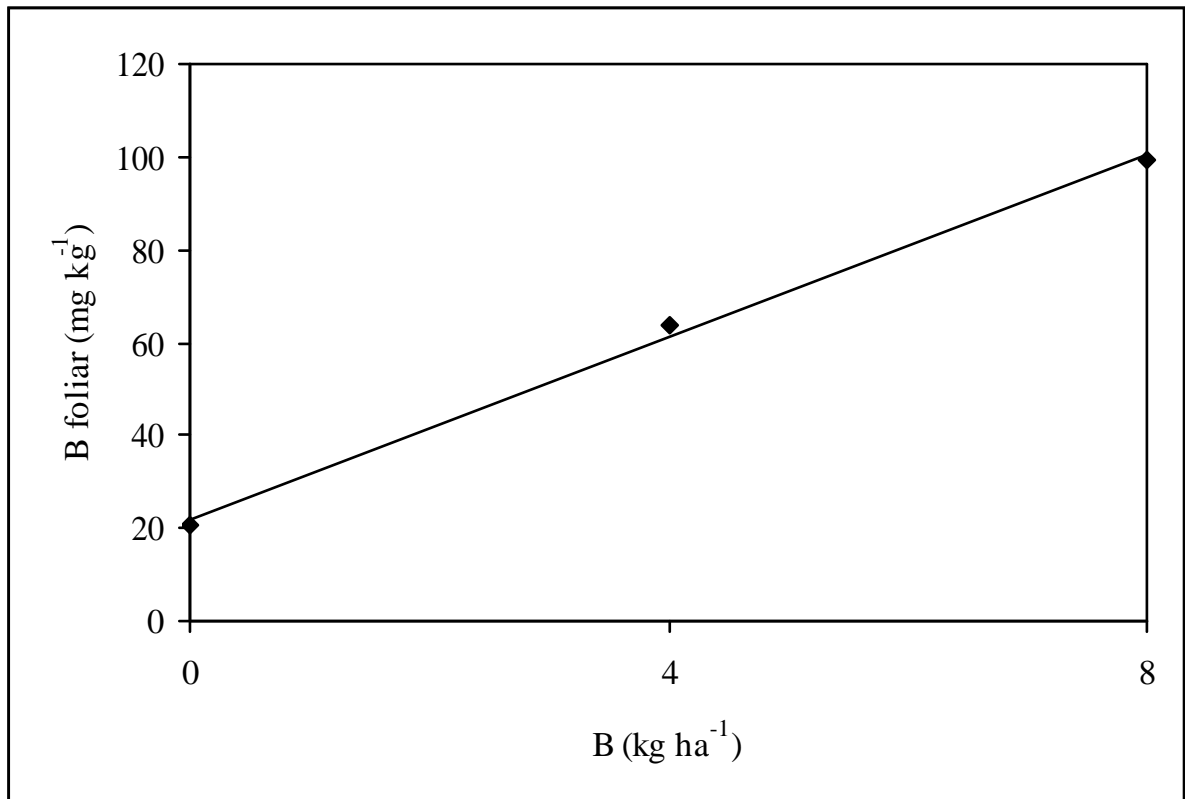

\begin{tabular}{|cccc|}
\hline Tratamento & $\mathrm{F}$ & $\mathrm{R} 2$ & Equação \\
\hline$\bullet \mathrm{B}$ & $252,32 * *$ & 0,9965 & $\mathrm{y}=22,0722+9,8025 \mathrm{x}$ \\
\hline
\end{tabular}

Figura 9 - Teor foliar de B $\left(\mathrm{g} \mathrm{kg}^{-1}\right)$ em função da aplicação de B.

\section{CONCLUSÕES}

A aplicação localizada de B na cova de plantio provocou sintomas de toxicidade nas plantas de brócolis 'BRO 68', reduzindo a massa média das inflorescências e a produção total.

Houve interação entre o $\mathrm{N}$ e o B na incidência de hastes ocas, cuja redução dessa anomalia foi maior quando se aplicou $8 \mathrm{~kg} \mathrm{ha}^{-1}$ de $\mathrm{B}$ em todas as doses de $\mathrm{N}$ e quando se aplicou $215,4 \mathrm{~kg} \mathrm{ha}^{-1}$ de $\mathrm{N}$ nas áreas não adubadas com $\mathrm{B}$.

\section{REFERÊNCIAS BIBLIOGRÁFICAS}

BABIK, I.; ELKNER, K. The effect of nitrogen fertilization and irrigation on yield and quality of broccoli. Acta Horticulurae, Amsterdam, v.571, p.33-43, 2002.

BATAL, K.M. et al. Nitrogen, magnesium, and boron applications affect cauliflower yield, curd mass, and hollow stem disorder. Hortscience, Alexandria, v.32, n.1, p.75-78, 1997.

BÉLEC, C. et al. Influence of nitrogen fertilization on yield, hollow stem incidence and sap nitrate concentration in broccoli. Canadian Journal Plant Science, Ottawa, v.81, p.765-772, 2001.
BRACY, P.R. et al. Sidress N application methods for broccoli production. Journal of Vegetable Crop

Production, Guildford, v.1, p.63-71, 1995.

EVERAARTS, A.P.; PUTTER, H. de. Fast growth results in more hollow stem in cauliflower. PVA Bulletin Vollegrondsroenteteelt, v.2, p.4-6, 2000.

FILGUEIRA, F.A.R. Novo manual de olericultura. Viçosa, MG: UFV, 2003. 402p.

FRACOIS, L.E. Effect of excess boron on broccoli, cauliflower and radish. Journal American Society for Horticultural Science, Madison, v.114, n.4, p.494-498, 1986.

GUPTA, U.C.; CUTCLIFFE, J.A. Boron nutrition in broccoli, Brussels sprouts and cauliflower grown on Prince Edward Island soils. Canadian Journal of Soil Science, Ottawa, v.53, p.275-279, 1973.

GUPTA, U.C.; CUTCLIFFE, J.A. Effects of applied and residual boron on the nutrition of cabbage and field beans. Canadian Journal of Soil Science, Ottawa, v.64, p.571-576, 1984. 
KOTUR, S.C. Nitrogen-Boron interaction in cauliflower (Brassica oleraceaI var. botrytis). Journal of the Indian Society of Soil Science, New Delhi, v.45, n.3, p.519-522, 1997.

MALAVOLTA, E.; VITTI, G.C.; OLIVEIRA, S.A. Avaliação do estado nutricional das plantas: princípios e aplicações. Piracicaba: Potafos, 1997. 201p.

MARSCHNER, H. Mineral nutrition of higher plants. London: Academic, 1995. 889p.

MELLO, S.C. et al. Influência do boro no desenvolvimento e na produtividade de cultivares de brócolis (Brassica oleracea var. italica). Científica, São Paulo, v.25, n.2, p.269-277, 1997.

PIZETTA, L.C. et al. Resposta de brócolis, couve-flor e repolho à adubação com boro em solo arenoso.

Horticultura Brasileira, Brasília, v.23, n.1, p.51-56, 2005.

SCAIFE, M.A.; WURR, D.C.E. Effects of nitrogen and irrigation on hollow stem of cauliflower (Brassica oleracea var botrytis). Journal of Horticultural Science, Cambridge, v.65, p.25-29, 1990.
SHATTUCK, V.I.; SHELP, B.J. Effect of boron nutrition on hollow stem in broccoli (Brassica oleracea var. italica). Canadian Journal of Plant Science, Ottawa, v.67, p.1221-1225, 1987.

SHELP, B.J. et al. Boron mobility in plants. Physilogoly Plantarum, Copenhagen, v.94, p.356-361, 1995.

TRANI, P.E.; RAIJ, B. van. Hortaliças. In: RAIJ, B. van; CANTARELLA, H.; QUAGGIO, J.A.; FURLANI,

A.M.C. (Eds.). Recomendações de adubação e calagem para o Estado de São Paulo. Campinas: Instituto Agronômico, 1996. p.157-164. (IAC. Boletim Técnico, 100).

TREMBLAY, N. Effect of nitrogen sources and rates on yield and hollow stem development in broccoli. Canadian Journal of Plant Science, Ottawa, v.69, p.1049-1053, 1989.

VIGIER, B.; CUTCLIFFE, J.A. Effect of boron and nitrogen on the incidence of hollow stem in broccoli. Acta Horticulturae, Amsterdam, v.157, p.303-308, 1984. 